\title{
OPEN Screening of core filter layer for the development of respiratory mask to combat COVID-19
}

\author{
Lokesh K. Pandey ${ }^{1}$, Virendra V. Singh ${ }^{1 凶}$, Pushpendra K. Sharma ${ }^{1}$, Damayanti Meher ${ }^{1}$, \\ Utpal Biswas ${ }^{1}$, Manisha Sathe ${ }^{1}$, Kumaran Ganesan ${ }^{1}$, Vikas B. Thakare ${ }^{1}$ \& Kavita Agarwal ${ }^{2}$
}

The severe outbreak of respiratory coronavirus disease 2019 has increased the significant demand of respiratory mask and its use become ubiquitous worldwide to control this unprecedented respiratory pandemic. The performance of a respiratory mask depends on the efficiency of the filter layer which is mostly made of polypropylene melt blown non-woven (PP-MB-NW). So far, very limited characterization data are available for the PPE-MB-NW in terms to achieve desired particulate filtration efficiency (PFE) against $0.3 \mu \mathrm{m}$ size, which are imperative in order to facilitate the right selection of PP-MB-NW fabric for the development of mask. In present study, eight different kinds of PP-MB-NW fabrics (Sample A-H) of varied structural morphology are chosen. The different PP-MB-NW were characterized for its pore size and distribution by mercury porosimeter and BET surface area analyzer was explored first time to understand the importance of blind pore in PFE. The PP-MB-NW samples were characterized using scanning electron microscopy so as to know the surface morphology. The filtration efficiency, pressure drop and breathing resistance of various PP-MB-NW fabric samples are investigated in single and double layers combination against the particle size of $0.3,0.5$ and $1 \mu \mathrm{m}$. The samples which are having low pore dia, high solid fraction volume, and low air permeability has high filtration efficiency $(>90 \%)$ against $0.3 \mu \mathrm{m}$ particle with high pressure drop (16.3-21.3 mm WC) and breathing resistance (1.42-1.92 mbar) when compared to rest of the samples. This study will pave the way for the judicial selection of right kind of filter layer i.e., PP-MB-NW fabric for the development of mask and it will be greatly helpful in manufacturing of mask in this present pandemic with desired PFE indicating considerable promise for defense against respiratory pandemic.

A new outbreak of corona virus disease (COVID-19), a viral contagious infection has engulfed many life globally and remain persist as major global threat to the human beings ${ }^{1}$. The disease is caused by infection with the severe acute respiratory syndrome coronavirus 2 (SARS-CoV-2) and primary transmission is through virusfilled respiratory aerosol droplets and can be produced by an infected person when coughs, sneezes, speaks or breathes, though specific mode of transmission is still debatable ${ }^{2-5}$. These aerosol droplets are having a different aerodynamic sizes, the droplet which has aerodynamic diameter more than $5 \mu \mathrm{m}$ settles due to gravity near the source and hence, it reduces the chances of spread, however the fine aerosol particle having aerodynamic size less than $5 \mu \mathrm{m}$ remain suspended in the environment for longer duration and play a key role for the spreading of infection ${ }^{6}$. Though the ultimate fate of aerosol particles are greatly influenced by the various environmental factors such as humidity, temperature, etc. which determine the virulence of aerosol particle ${ }^{2}$.

In the past also world has witnessed many deadliest outbreak including cholera, Spanish flu, Ebola etc. and now corona outbreak has raised a serious threat for human life and emerged as a major challenge for the scientific fraternity to control its widespread infection ${ }^{7}$. The World Health Organization (WHO) on March 11, 2020 declared that the COVID-19 is a pandemic and had endangered more than 218 countries and territories affecting more than 6.4 crore human life around the world and the sustained risk of further global spread ${ }^{8}$. Government regulatory authorities are working on the World Health Organization's (WHO) guidelines and has taken a protective measure to prevent this world disaster unleash spread of deadliest corona pandemic by advancement in sanitization and public hygiene and take a serious measures in terms of isolation, quarantines etc. along with the use of appropriate personal protective equipment for healthcare workers in practice $e^{9,10}$. Amidst the lack of vaccine against this COVID-19, personal hygiene and use of facemask have been suggested

${ }^{1}$ Defence Research and Development Establishment, DRDO, Jhansi Road, Gwalior 474002, India. ${ }^{2}$ Defence

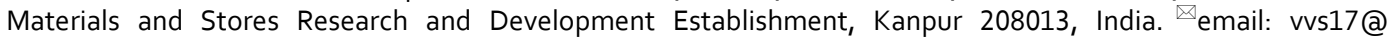
drde.drdo.in 
as important mitigation strategies against this type of respiratory infection, however, uncertainties exist for the mode of transmission of COVID-19 ${ }^{11,12}$. In the wake of the COVID-19 pandemic, the US center for disease control and prevention recommends the use of face masks as a physical barrier in public places to prevent its onward transmission ${ }^{13}$. The purpose of physical respiratory protection is to limit the exposure of individuals against particular threat and it works on twin aspects of protection (i) establishment of artificial barrier: filter layer (melt blown) and (ii) supply of breathable air. In this COVID-19 pandemic, respiratory masks core layer i.e. filter layer significantly improves the protection of front line fighters in mitigating this spread of coronavirus via respiratory droplets ${ }^{14,15}$. These airborne aerosol particles are trapped by filter layer of mask through a combination of the following mechanisms: Interception, Sedimentation, Impaction and Diffusion ${ }^{16}$. In general, the efficiency of the aerosol retention depends on the fiber diameter of the medium, particle size of the aerosols, and rate of airflow through the filter ${ }^{17}$. The filtering facepiece respirators (FFRs) as per the US National Institute for Occupational Safety and Health (NIOSH) classifies particulate into various categories (N95, N99, N100, P95, P99, $\mathrm{P} 100, \mathrm{R} 95, \mathrm{R} 99$, and R100) ${ }^{18}$ where, $\mathrm{N}$ refers that the respirators is not resistant to oil droplet; R refers resistant to oil droplet, $\mathrm{P}$ is completely resistant to oily aerosols and numerical digit indicates the percentage minimum filtration efficiency ${ }^{19}$. However, BIS standard (IS 9473:2002) classifies filtering half mask into three classes: FFP1, FFP2, and FFP3 with corresponding minimum filtration efficiencies of $80 \%, 94 \%$, and $97 \%{ }^{20}$. The lock down due to COVID-19 severely affects the production and supply of face masks throughout the world ${ }^{21}$ and its worldwide shortage during the COVID-19 outbreak has become a social concern ${ }^{21,22}$. Many industries which were not involved in this business have also entered in to this sector for fulfilling the scarcity of mask in the market. However, due to the lack of judicial selection of filter material of mask, design, inadequate knowledge of different layers of mask, impeded the fast development and production of facemask by the start-up industries. In order to ensure the availability of mask during the COVID-19 outbreak, the knowledge about the different component of facemask is very critical to intensify efforts to develop effective facemask which ensure the highest possible user comfort along with high $\mathrm{PFE}^{22}$. In facemask, filter layer is the vital component and plays a very important role for determining the filtration efficiency ${ }^{22}$. Filter layer can be made up of different material starting from polypropylene and polyethylene melt blown non woven/woven/knitted, HEPA, PTFE (Polytetrafluoroethylene) etc. $^{23,24}$. Each filter layer material is having its own advantages and disadvantages ${ }^{24}$. Among this filter layer material, nonwoven materials are known to be pertinent structures for fine filtration and moderate pressure drop ${ }^{24}$. In order to develop a filter that combines good permeability and high efficiency, polypropylene non woven melt blown are of great interest because of its fine mesh structural parameters, excellent filtration properties, thermal insulation, and sorption capacity and allowing the wearer to breath while reducing the inflow of possible infectious particles ${ }^{25-27}$. Polypropylene (PP) melt blown non woven is the most widely used polymer for this process, since it is relatively inexpensive and versatile enough to produce a wide range of products ${ }^{25-27}$. Others, such as polyethylene (PE), poly(ethyleneterephthalate) (PET), poly(butyleneterephthalate) (PBT), polystyrene (PS), polyurethane (PUR), and polyamide (PA) can also be used to produce melt blown webs ${ }^{28}$. Moreover, non-woven fabric forming technology is cheaper than other fabric forming technology like woven or knitted. Nonwovens are considered as better filter material than woven fabrics owing to its cost effective, cheaper to produce, versatile and offer a wide range of functionalities. Using melt blown technology, hydrophilic and hydrophobic materials can be produced and by incorporating additives it will improve filtration efficiency, moisture adsorption, and biocidal properties ${ }^{25,26}$. It has been observed that in PP-MB-NW, fiber diameter, pore size, and areal density have played a very crucial role on the performance of the filter nonwoven in terms of protective and functional parameters ${ }^{29}$. Hence, the objective of present work is to understand and investigate the filtration efficiency behavior of commercially available different PP-MB-NW which is strongly influenced by its fiber diameter, pore size, pore distribution and air permeability.

Herein, different characteristic properties of PP-MB-NW including pore size, pore diameter, air permeability, filtration efficiency at different aerosol particle size are studied and a relationship was established to its particulate filtration efficiency (PFE). For this purpose, different thickness, areal density, pore size and pore diameters PP-MB-NW are subjected to filtration efficiency test against different aerosol particles. Surface area analysis was carried out for the first time in order to get more insight about the pore having a dimension between 17-3000 and total area in pore $11.79 \AA$ which were not possible with porosimeter. PFE of PP-MB-NW were evaluated in single layer and combination thereof against aerosol particulate sizes ranges from 0.3 to $10 \mu \mathrm{m}$ range, which is particularly relevant for respiratory virus transmission. The PP-MB-NW samples were characterized using scanning electron microscopy (SEM) so as to know the surface morphological characteristics. The study will be imperative as it provides information and understanding about the core layer of respiratory mask, which are keenly looked by the industries or manufacture to explore the right kind of PP-MB-NW fabric to achieve required filtration efficiency.

\section{Experimental}

Chemical and materials. The polypropylene (PP) melt blown nonwoven fabric of different structural characteristic was provided by the commercial Indian Industry. Sodium chloride purity ( $\geq 99.0 \%)$ was purchased from Sigma-Aldrich, India. Milli-Q water was utilized to prepare sodium chloride solutions.

Instrumentation and material characterization. ESEM (Make: Carl ZEISS EVO 15 LVSM, Germany) system was used for the surface and structural morphology of the PPE MB nonwoven. The pore size and its distribution were characterized by Mercury porosimeter (Porous Materials Inc, USA). The BET surface area were measured using surface area analyzer (ASAP 2020, Micrometrics, USA). The differential pressure across the PP-MB-NW fabric was measured using pressure meter (Testo 510 absolute Pressure meter, USA). Lighthouse Worldwide Solutions, USA Model No. handheld 2016 was used for the aerosol particle size and concentration. 
Air permeability of the samples was measured using an Air permeability tester (Make: Asian Equipment, Ghaziabad, India).

Pressure drop and breathing resistance. Pressure drop was measured by pressure meter through a sample by measuring the difference between downstream and upstream air at constant flow rate. Prior to the experiment, samples are conditioned for a minimum of $24 \mathrm{~h}$ by exposure to a temperature of $25 \pm 1{ }^{\circ} \mathrm{C}$ and a relative humidity of $85 \pm 5 \%{ }^{30}$. The samples are allowed to return at room temperature for at-least $4 \mathrm{~h}$ between exposure and prior to subsequent testing. Breathing resistance was measured by breathing resistance assembly fabricated using IS 9473:2002. The samples were sealed on dummy head. To simulate inhaled air, a vacuum pump pulled air from outside to the inside of the mask at $95 \mathrm{l} / \mathrm{min}$ continuous flow of air. Three replicate of each PP-MB-NW filter layer were tested at ambient experimental condition at $95 \mathrm{lpm}$ continuous flow of air using pressure transducer.

Characterizations of PP-MB-NW fabric. The physical properties of the PP-MB-NW fabric were investigated as per the standard test method. The areal density of the PP-MB-NW was measured by ASTM D 6492-98 and the air permeability was measured by ASTM D 737-0 $4^{31}$. The solid volume fraction of the PP-MB-NW was calculated using equationn ${ }^{32}$ :

$$
\alpha=10 \times \mathrm{G} / \mathrm{P}_{\mathrm{f}} \times \mathrm{Z}
$$

where, $G=$ mass per unit area, $P_{f}=$ fiber density $\left(\mathrm{g} / \mathrm{cm}^{3}\right)$, and $Z=$ thickness of the fabric, $\mathrm{mm}$.

Fabric's areal density (mass per unit area) was measured according to ASTM D3776-09 standard. Each specimen was cut into $5 \mathrm{~cm}^{2}$ size using a template and weighed by an electronic balance.

$$
\rho=\mathrm{m} / \mathrm{A}
$$

where, $\rho$ is areal density $\left(\mathrm{g} / \mathrm{m}^{2}\right), \mathrm{m}$ is the mass in $\mathrm{g}$ and $\mathrm{A}$ is the fabric area in $\mathrm{m}^{2}$. Five measurements were conducted for each PP-MB-NW fabric.

Area of test material and face velocity for particulate filtration efficiency. To determine the particular filtration efficiency of different PP-MB-NW, a specimen of $3.14 \mathrm{~cm}^{2}$ area was taken from the PP-MB-NW samples by considering the surface area of a typical facemask as approximately $150 \mathrm{~cm}^{2}$ as reported elsewhere ${ }^{33}$. Based on the area of mask, flow rate was calculated for particular specimen and it was 4.5 LPM, representative of 95 LPM. Three samples of each PP-MB-NW were tested for its filter performance. From the mean penetration value, the percentage efficiency was calculated for each melt blown individual and combination thereof.

Determination of particulate filtration efficiency. Figure 1 illustrate the role of various layers of respiratory mask against different particle size with emphasis to core layer i.e. PP-MB-NW against most penetrating particle size of $0.3 \mu \mathrm{m}$. The filtration efficiency and pressure drop of PP-MB-NW was tested by using $\mathrm{NaCl}$ test rig ${ }^{34}$. The schematic view of the $\mathrm{NaCl}$ Test Rig is given in Fig. 2. The test rig consists of the compressor, air receiver, dry air unit, flow meter, control valve, air ducts, aerosol generator, particle counter, and digital manometer etc. as shown in Fig. 2. The dry and clean air was obtained from compressor through HEPA filter and fed to the air regulator. The required airflow is adjusted by means of flow meter and flow control valve. $\mathrm{NaCl}$ was used to generate aerosol and the size of aerosol ranging from 0.3 to $10 \mu \mathrm{m}$. The test aerosol of $\mathrm{NaCl}$ is generated by compressed air atomisation using glass nebuliser. The generator/pump when operated at an air pressure of $1.76 \mathrm{~kg} \mathrm{~cm}^{2}$ (approx) ensures production of $\mathrm{NaCl}$ aerosol in the sub micron range with Mass Median Diameter (MMD) of $0.3 \mu \mathrm{m}$. The PFE of different PP-MB-NW was measured by laser particle counter by taking the difference of particles from up and down air stream of respiratory mask ${ }^{35}$. The air filtration efficiency is calculated using following equation:

$$
\text { Particulate filtration efficiency }(\%)=[(\mathrm{C} 1-\mathrm{C} 2) /(\mathrm{C} 1)] \times 100
$$

where $\mathrm{C} 1$ is the number of $\mathrm{NaCl}$ particle in upstream counts and $\mathrm{C} 2$ is the number of $\mathrm{NaCl}$ particle in downstream counts.

\section{Results and discussion}

Influence of structural characteristics of PP-MB-NW fabric. In order to know the effect of structural characteristics of PP-MB-NW fabric on filtration PFE, structural characteristic such as thickness, areal density and solid volume fraction $(\alpha)$ were studied and tabulated in Table $1^{17,36,37}$. Areal density is an important factor which affects the fluid flow through a nonwoven and it also affects the air permeability ${ }^{38}$. Areal density is also affected by thickness and density of the fibers and finally affects the $\alpha^{37}$. Hence, all these structural parameters are interrelated. As can be seen from the Table 1 the areal density and thickness of the PP-MB-NW samples A-H were varied from 18-60 GSM and 0.08-0.350 mm, respectively. Since, thickness and areal density in combination has ability to affect $\alpha$ or porosity of a fabric. Therefore, a which is also referred as packing density of the fabric are also calculated and showed in Table 1. The a values of samples A-H are calculated and found that it varied from 1980 to 3700 . In general, as the areal density increases the a value should also increase, however in this study, regular trend is not observed due to difference in thickness (increase in thickness decreases the $\alpha$ value). However, In sample $\mathrm{A}$ and $\mathrm{C}$, the $\alpha$ is at higher side from rest of the samples which reflects the greater degree of compactness of the fabric due to high packing density which could decreases the air permeability and 


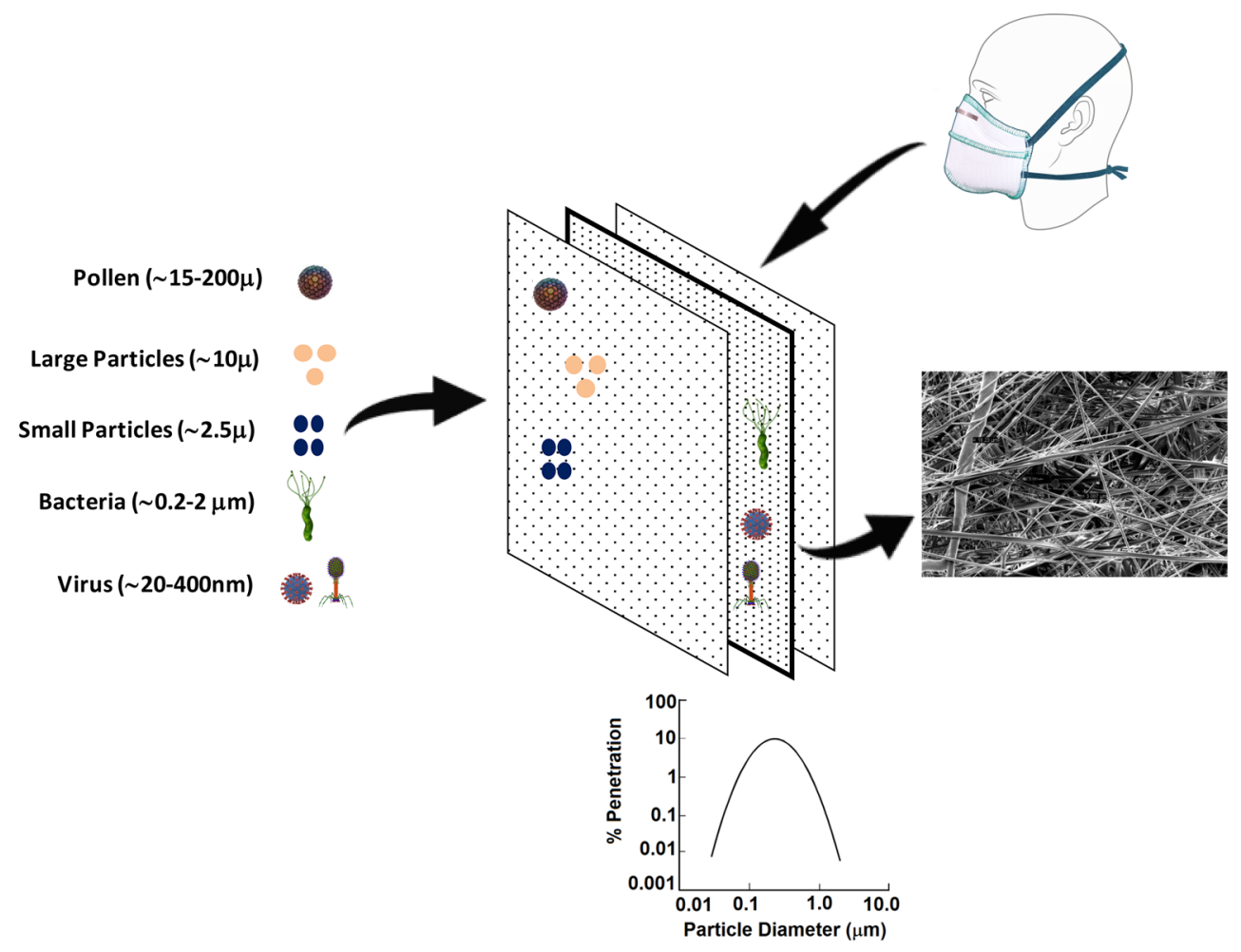

Figure 1. Schematic representation of the respiratory mask showing the various layers and importance of differ layer of mask with emphasis of PP-MB-NW against most penetrating particle size (drawn using Microsoft Office 2007 and Solid Edge version 4).

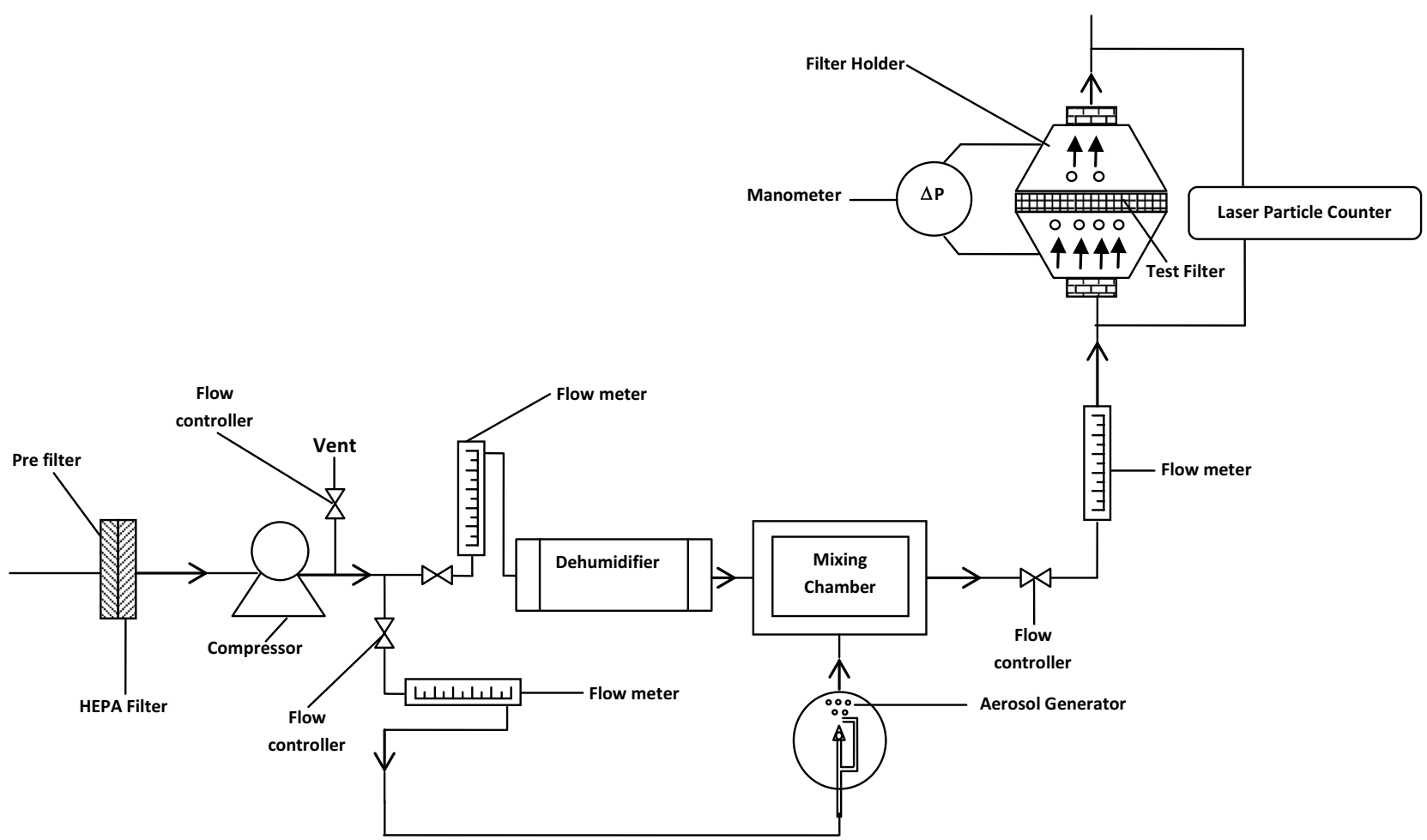

Figure 2. Schematic of the aerosol filtration efficiency test setup (drawn using Microsoft Office 2007). 


\begin{tabular}{|l|l|l|l|l|}
\hline S. no. & Sample code & Thickness $(\mathbf{m m})$ & Aerial density $\left(\mathbf{g} / \mathbf{m}^{2}\right)$ & Solid volume fraction $(\boldsymbol{\alpha})$ \\
\hline 1 & A & 0.080 & 25 & 3703.70 \\
\hline 2 & B & 0.100 & 28 & 3094.60 \\
\hline 3 & C & 0.120 & 30 & 2818.51 \\
\hline 4 & D & 0.140 & 30 & 2412.92 \\
\hline 5 & E & 0.080 & 18 & 2584.08 \\
\hline 6 & F & 0.250 & 50 & 2332.4 \\
\hline 7 & G & 0.140 & 30 & 2412.92 \\
\hline 8 & H & 0.350 & 60 & 1983.17 \\
\hline
\end{tabular}

Table 1. Structural characteristic of PPE melt blown non woven.

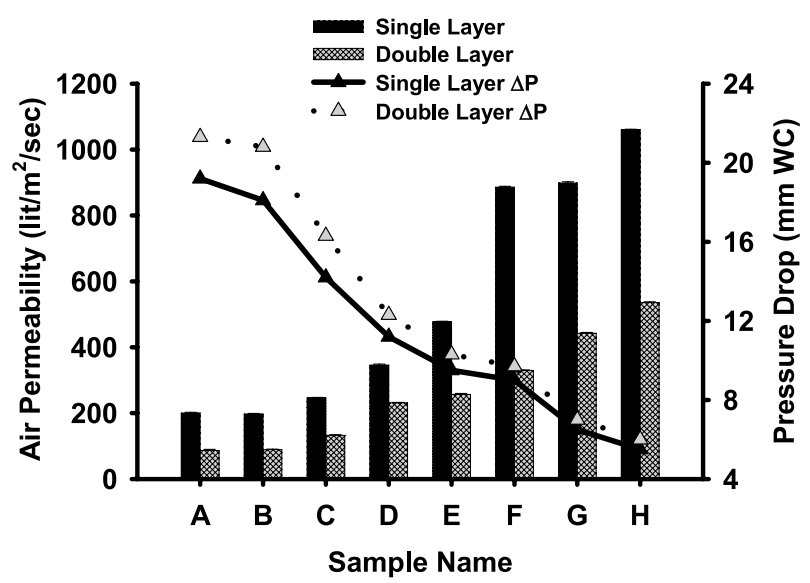

Figure 3. Air permeability and pressure drop of various PP-MB-NW fabric sample $(A-H)$ in single and double layers. The error bars represent the standard deviation of three measurements.

in turn increases the filtration efficiency ${ }^{39,40}$. Hence, from the above data it can infer that the sample A and C may have lower air permeability with high filtration efficiency ${ }^{41}$.

Influence of structural characteristics of PP-MB-NW fabric. There is limited research on the effect of PP-MB-NW fabrics thickness, solid volume fraction and porosity over air permeability of non woven structure in technical textiles ${ }^{42}$. In general, it has been reported by some of research group that there is a non linear relationship between air permeability and thickness and solid volume fraction ${ }^{43,44}$, though it has also been found that air-permeability is almost inversely proportional to the mass per unit area ${ }^{45}$. However, it is rational to expect that air permeability is strongly dependent on non woven microstructural parameters such as porosity, fiber size, solid volume fraction and fiber arrangement as air permeability governs the air resistance or the pressure drop of the air through fabric ${ }^{36,46}$. In general, respiratory mask is comprised of layers, from outer to inner: an outer hydrophobic layer spun bound followed by 2 melt blown non woven layer (PP-MB-NW) as a filter layer, in between the filter layer, one support layer that provides rigidity and adds thickness to the mask, giving it more structure and adding to the feel of comfort. The innermost layer is another hydrophobic non-woven polypropylene layer which minimizes moisture within the mask from entering the mask material.

The air permeability and pressure drop of PP-MB-NW samples (A-H) were measured according to ASTM $\mathrm{D} 73^{47}$. As can be seen from the Fig. 3 and Table 2 the air permeability of sample A to D is varying from 197.24 to $345.84 \mathrm{l} / \mathrm{m}^{2} / \mathrm{s}$ in single PP-MB-NW samples while in combination of double layer it varied from 86.67 to $213.17 \mathrm{l} / \mathrm{m}^{2} / \mathrm{s}$. While in sample $\mathrm{E}$ to $\mathrm{H}$ air permeability increased from $477.04 \mathrm{l} / \mathrm{m}^{2} / \mathrm{s}$ to $1060.76 \mathrm{l} / \mathrm{m}^{2} / \mathrm{s}$ in single layer and in double layer it increases from 257.09 to $535.801 / \mathrm{m}^{2} / \mathrm{s}$. As it is observed from Fig. 3, as air permeability increases, pressure drop decreases as it is inversely proportional to the air permeability. This difference in air permeability and pressure drop is due to meltblown technology which enables production of webs having finer fibers with higher surface area, and different degree of interlacing. The decrease in air permeability using 2 melt blown layer is attributed by multilayered structures behaved as a barrier to hinder the flow of air through the structure. The differences in air permeability of the samples are may be due to differences in pore sizes and compactness of these samples. As can been seen from the Table 2, samples A to C are having lower air permeability when compared to rest of the samples and small difference in air permeability of the samples, one can expect that there may be a small variation in pore size, compactness and interlacing in between fibers and may have little variation in $\mathrm{PFE}^{48,49}$. The above findings are well supported by solid volume fraction of the various PP-MB-NW samples. As in sample A and B the a value was greater than rest of the samples. In order to get more 


\begin{tabular}{|c|c|c|c|}
\hline S. no. & Sample code & Sample layers & Air permeability @ $12.7 \mathrm{~mm} \mathrm{WG}\left(1 / \mathrm{m}^{2} / \mathrm{s}\right)$ \\
\hline \multirow{2}{*}{1} & \multirow{2}{*}{ A } & Single layer & 200.24 \\
\hline & & Double layer & 86.67 \\
\hline \multirow{2}{*}{2} & \multirow{2}{*}{ B } & Single layer & 197.24 \\
\hline & & Double layer & 89.33 \\
\hline \multirow{2}{*}{3} & \multirow{2}{*}{ C } & Single layer & 246.47 \\
\hline & & Double layer & 132.67 \\
\hline \multirow{2}{*}{4} & \multirow{2}{*}{$\mathrm{D}$} & Single layer & 345.84 \\
\hline & & Double layer & 213.17 \\
\hline \multirow{2}{*}{5} & \multirow{2}{*}{ E } & Single layer & 477.04 \\
\hline & & Double layer & 257.09 \\
\hline \multirow{2}{*}{6} & \multirow{2}{*}{$\mathrm{F}$} & Single layer & 885.67 \\
\hline & & Double layer & 329.62 \\
\hline \multirow{2}{*}{7} & \multirow{2}{*}{ G } & Single layer & 898.51 \\
\hline & & Double layer & 442.25 \\
\hline \multirow{2}{*}{8} & \multirow{2}{*}{$\mathrm{H}$} & Single layer & 1060.76 \\
\hline & & \begin{tabular}{|l|} 
Double layer \\
\end{tabular} & 535.8 \\
\hline
\end{tabular}

Table 2. Air permeability of PPE melt blown non woven samples as per ASTM D73.

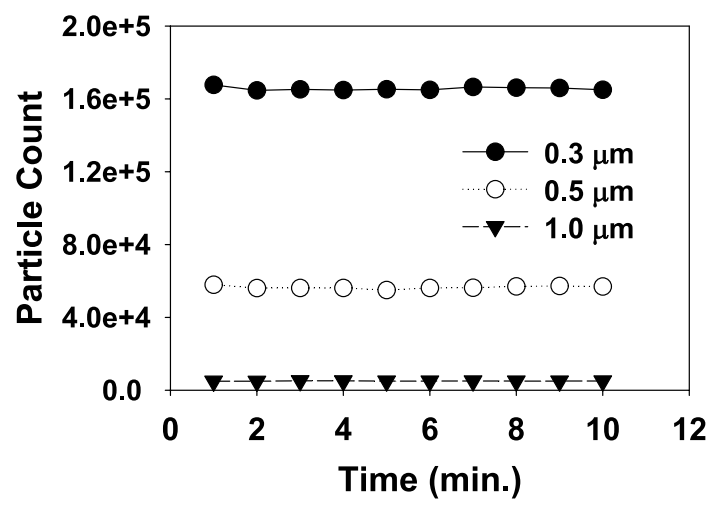

Figure 4. Stability studies of generated $\mathrm{NaCl}$ aerosol particle size $0.3,0.5$ and $1 \mu \mathrm{m}$.

insight of packing density, fiber diameter, degree of entanglements and distance between the fibers which can greatly influence the air permeability of PP-MB-NW fabrics, it was further characterized for its surface morphology using SEM in subsequent section.

Particulate filtration efficiency of filter layer (PP-MB-NW). The filtration efficiency for all the eight PP-MB-NW samples was measured using the $\mathrm{NaCl}$ aerosol method as a function of particle size. Prior to the experiment, samples are conditioned for a minimum of $24 \mathrm{~h}$ by exposure to a temperature of $25 \pm 1{ }^{\circ} \mathrm{C}$ and a relative humidity of $85 \pm 5 \%{ }^{30}$. The samples are allowed to return at room temperature for at-least $4 \mathrm{~h}$ between exposure and prior to subsequent testing. The filtration efficiency of the samples has been tested for the particle size of $0.2 \mu \mathrm{m}, 0.3 \mu \mathrm{m}, 0.5 \mu \mathrm{m}$ and $1 \mu \mathrm{m}$. The reason to choose $0.3 \mu \mathrm{m}$ size particle for PFE is to target the respiratory droplet of Sars-COV-2 coronavirus which is larger than $0.3 \mu \mathrm{m}$. The concentration of the upstream and downstream particles of sizes $0.2 \mu \mathrm{m}, 0.3 \mu \mathrm{m}, 0.5 \mu \mathrm{m}$ and $1 \mu \mathrm{m}$ were measured using the optical laser particle counter. In order to determine PFE, stabilization of generated aerosol particle size $0.3 \mu \mathrm{m}, 0.5 \mu \mathrm{m}$ and $1 \mu \mathrm{m}$ is very important and it was studied for a period of $10 \mathrm{~min}$ as given in Fig. 4 . As can be seen from the Fig. 4, the generated $\mathrm{NaCl}$ particle of different sizes are stable and observed approximately same number of particles. After stabilization of generated aerosol particle, the samples are challenged for three particle sizes of $0.2,0.3,0.5$ and $1 \mu \mathrm{m}$. The aerosol generator can be adjusted to generate the desired concentrations of particle for testing, which are enumerated using the particle counter downstream of the test sample. The aerosol was passed through a drying chamber, diluted to the required concentration using pre filtered air and then passed through the sample. The challenge flow was same as reported in IS 9473:2002. Three replicate of each PP-MB-NW filter layer were tested at ambient experimental condition. The PFE of individual PP-MB-NW layer and their combination was determined as a function of particle size by measuring the upstream concentration and downstream concentration. Table 3 details the results obtained with the individual and its combination of PP-MB-NW layer for PFE, Differential Pressure $(\Delta \mathrm{P})$ and breathing inhalation resistance (BIR). The $\Delta \mathrm{P}$ and BIR across PP-MB-NW layer was measured to determine the comfort level of wearer and the suitability of materials to fabricate the mask. 


\begin{tabular}{|c|c|c|c|c|c|c|c|c|}
\hline \multirow[b]{2}{*}{ S. no. } & \multirow[b]{2}{*}{ Sample code } & \multirow[b]{2}{*}{ Sample layers } & \multicolumn{4}{|c|}{ PFE (\%) } & \multirow{2}{*}{$\begin{array}{l}\Delta \mathbf{P} \\
\mathbf{m m W C}\end{array}$} & \multirow{2}{*}{$\begin{array}{l}\text { Breathing inhalation resistance (BIR) } \\
\text { mbar }\end{array}$} \\
\hline & & & $0.2 \mu \mathrm{m}$ & $0.3 \mu \mathrm{m}$ & $0.5 \mu \mathrm{m}$ & $1.0 \mu \mathrm{m}$ & & \\
\hline \multirow{2}{*}{1} & \multirow{2}{*}{ A } & Single layer & 93.37 & 94.33 & 98.44 & 99.41 & 19.2 & 1.85 \\
\hline & & Double layer & 97.25 & 98.61 & 99.13 & 99.99 & 21.3 & 1.92 \\
\hline \multirow{2}{*}{2} & \multirow{2}{*}{ B } & Single layer & 92.62 & 93.56 & 97.50 & 99.64 & 18.1 & 1.72 \\
\hline & & Double layer & 98.80 & 99.59 & 99.95 & 99.95 & 20.8 & 1.88 \\
\hline \multirow{2}{*}{3} & \multirow{2}{*}{ C } & Single layer & 82.62 & 83.85 & 94.08 & 97.59 & 14.2 & 1.42 \\
\hline & & Double layer & 94.60 & 95.67 & 99.08 & 99.72 & 16.3 & 1.52 \\
\hline \multirow{2}{*}{4} & \multirow{2}{*}{$\mathrm{D}$} & Single layer & 42.29 & 43.37 & 69.43 & 85.07 & 11.2 & 0.89 \\
\hline & & Double layer & 58.92 & 59.85 & 81.81 & 94.19 & 12.3 & 0.95 \\
\hline \multirow{2}{*}{5} & \multirow{2}{*}{$\mathrm{E}$} & Single layer & 29.90 & 30.76 & 56.21 & 79.50 & 9.5 & 0.69 \\
\hline & & Double layer & 46.02 & 46.94 & 76.04 & 93.57 & 10.3 & 0.73 \\
\hline \multirow{2}{*}{6} & \multirow{2}{*}{$\mathrm{F}$} & Single layer & 23.18 & 24.04 & 44.05 & 69.18 & 9.0 & 0.55 \\
\hline & & Double layer & 37.25 & 38.73 & 61.87 & 83.67 & 9.7 & 0.58 \\
\hline \multirow{2}{*}{7} & \multirow{2}{*}{ G } & Single layer & 14.65 & 15.5 & 24.84 & 46.19 & 6.5 & 0.54 \\
\hline & & Double layer & 35.17 & 36.00 & 55.75 & 75.85 & 7.0 & 0.57 \\
\hline \multirow{2}{*}{8} & \multirow{2}{*}{$\mathrm{H}$} & Single layer & 19.21 & 20.41 & 41.46 & 67.22 & 5.5 & 0.44 \\
\hline & & Double layer & 30.89 & 32.16 & 56.00 & \begin{tabular}{|l|}
83.19 \\
\end{tabular} & 6.0 & 0.51 \\
\hline
\end{tabular}

Table 3. Particulate filtration efficiency, $\triangle \mathrm{P}$ and breathing inhalation resistance of PPE melt blown non woven samples.

Figure 5 and Table 3 shows that, in case of Sample A and B, the PFE of single layer MB against $0.2 \mu \mathrm{m}$ is 93.37 and $92.62 \%$ and against $0.3 \mu \mathrm{m}$ is $94.10 \%$ and $93.06 \%$, respectively, while keeping another layer of $\mathrm{MB}$, the PFE increased to $>99 \%$ in both the samples. This observation suggests that, the second layer does not increase PFE significantly; however, the second layer is important to meet the desired PFE as per NIOSH and IS standard. For sample A, the PFE for 0.5 and $1 \mu \mathrm{m}$ particles are reached against approx 98-99\% even in single layer and in combination thereof. Increasing the number of layers (as shown for Fig. 5 and Table 3), as expected, improves the PFE performance. In sample C, the PFE against $0.3 \mu \mathrm{m}$ particle is $83.94 \%$ with single layer and increased to 95.70\% using double layer of the same sample. The PFE for size in between 0.5 to $1 \mu \mathrm{m}$ is varies from 94.06 to 99.09\% using single and double layer. The PFE for samples D, E, F, G and H for single layer is 43.37, 30.76, 24.04, 15.5 and $20.41 \%$ and it increased to $59.85,46.94,38.73,36.00$ and 32.16 for double layer samples, respectively. It has also been observed from Table 3, for $0.2 \mu \mathrm{m}$ size particle the PFE is approx same as $0.3 \mu \mathrm{m}$ and similar trend was reported earlier. Higher PFE values were obtained with sample A to C which may be due to highly compact structure of MB with higher degree of entanglement which may lead to decrease in pore dia and distance between fabrics, this results are in agreement with a value of Table 1. Moreover, this wide variation in filtration efficiency for different samples can be attributed by the surface properties of the fibers which play a major role on filtration and the fibers in each layer of non woven fabric and its surface morphology is responsible for filtration performance. The value of $\Delta \mathrm{P}$ and BIR of the samples are having high PFE are more when compared to samples $(\mathrm{D}-\mathrm{H})$ are having a low PFE, nevertheless the values are in the limit of IS 9473:2002. The $\Delta \mathrm{P}$ and BIR value also support the compactness and high degree of entanglement of PP-MB-NW fabric in sample A-C. In order to further understand the filtration efficiency behavior of different PP-MB-NW samples, pore size, BET surface area analysis and SEM characterization studies were performed and discussed in subsequent sections.

Pore size determination using mercury porosimeter. The pore structure and its size plays a very crucial role in performance of PP-MB-NW fabric making this as a most important structural feature ${ }^{50}$. These pore structure is internally connected by three-dimensional network of capillary channels of non-uniform dimensions. In PP-MB-NW fabric fabrics, pore can be classified into three categories namely blind pores, through pores and closed pores. The blind and through pores are playing significant role in PFE. In order to confirm the above finding, mercury porosimeter was used to determine the pore size of different samples ${ }^{51}$. In general pore size decreases due to higher specific surface area of lower fiber diameter ${ }^{49}$. The porosimeter determines both pressure and flow and record these in a pressure versus flow graph for wet and dry sample ${ }^{51-53}$. The dry data curves are determined after all the liquid expelled from the pores. These dry curves become the reference for calculating the pore distribution ${ }^{51-53}$. After measuring the pressure, air flow rate for dry and wet samples, pore size, and pore size distribution are calculated by the software. The results of mercury porosimeter are shown in Fig. 6 and summarized in Table 4 .

Figure 6 shows the curve between pore size distributions versus the pore diameter in order to elucidate the major contribution of pores in filtration efficiency as pore size plays a very crucial role. Table 4 depicts the pore size distribution of various samples of PP-MB-NW fabric in terms of maximum pore size and mean pore size. As can be seen from Fig. 6, in sample A-C, the pore size showed a relatively narrow range, the mean and maximum pore sizes were varied from 8.80 to $10.51 \mu \mathrm{m}$ and 12.49 to $18.65 \mu \mathrm{m}$, respectively. In sample A, the largest peak exists of $9.5-10.0 \mu \mathrm{m}$ and some major peak between the pore size from 9 to $10 \mu \mathrm{m}$, indicating maximum contribution of $9.0-10 \mu \mathrm{m}$ pore diameter the most to the porosity followed by other pore diameter. In 

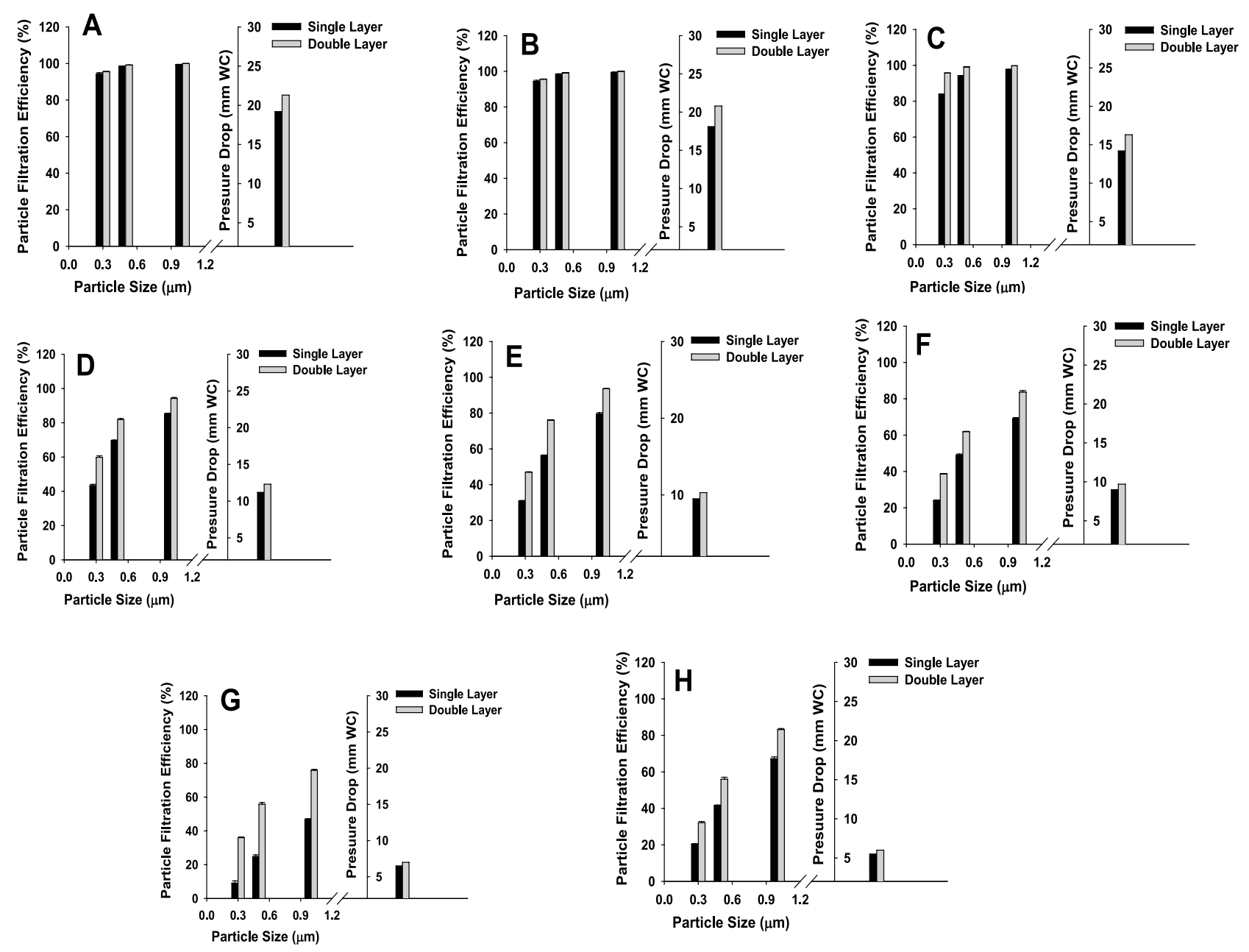

Figure 5. Particulate filtration efficiency and pressure drop of various PP-MB-NW fabric sample (A-H) in single and double layers: Fig. 5A-H: PFE of sample A, B, C, D, E, F, G and H in single and in double layer against $\mathrm{NaCl}$ aerosol particle size $0.3,0.5$ and $1 \mu \mathrm{m}$. The error bars represent the standard deviation of three measurements.

sample B (Fig. 6), largest peak of pore size diameter start from 8.4 to $9 \mu \mathrm{m}$, and it contribute most of the porosity in the sample. Likewise in sample C, D, E, F, G and $\mathrm{H}$ the most contributing pore diameters are 10-11 $\mu \mathrm{m}$, $11.5-13.0 \mu \mathrm{m}, 13-15 \mu \mathrm{m}, 14-15.5 \mu \mathrm{m}, 18-19.5 \mu \mathrm{m}$ and 30-32 $\mu \mathrm{m}$, respectively. As can be seen from the above, there is an increasing trend in pore diameter from sample $\mathrm{A}$ to $\mathrm{H}$ and similar tends are also observed in the air permeability from sample A-H. This increment in mean pore size was also supported by solid volume fraction and air permeability data shown in Tables 1 and 2, respectively. Furthermore, PFE behaviors of different PP-MBNW samples (A-H) are also supported by the above data, as fiber diameter plays a significant effect on filtration efficiency properties. Low fiber diameter leads to better filtration efficiency owing to higher entanglement and higher surface area as observed in case of samples A-C. This data also confirmed that the air permeability is inversely proportional to mean pore dia of the nonwoven $\mathrm{PP}$, as reported elsewhere ${ }^{38}$. Moreover, the difference in maximum pore size and mean pore size of the samples are attributed by the influence of sample material, surface morphology, operation process and the use of wetting agent ${ }^{54}$.

BET surface area characterization of PP-MB-NW. Using mercury porosimeter, the through pore diameter can be only measured up to the range of micron size only. However, the smaller pore diameter including blind pore cannot be characterized by utilizing mercury porosimeter as these pores are not accessible by the fluid to flow through them. Hence, the size of blind pore cannot be determined. In order to understand the PFE behavior sometime porosimeter and air permeability data along with microstructures details above are not sufficient enough to characterize the MB for its behavior. Hence, BET surface area analyzer was used to characterize and overcome the above limitation of porosimeter as blinds pores are also responsible for filtration efficiency. In order to understand and to get more insight in particular, the pore sizes which are below the limit of porosimeter, pore having a dimension between $17-3000 \AA$ and total area in pore $11.79 \AA$ were calculated. As can be seen from the Table 5, the sample A and B the total area of pores $11.79 \AA$ are more than $20 \mathrm{~m}^{2} / \mathrm{g}$ with BJH desorption Cumulative volume of pores between $17.0 \AA$ and $3000 \AA$ width approx more than $0.031 \mathrm{~cm}^{3} / \mathrm{g} \mathrm{are}$ having good filtration efficiency. The resultant data from above characterization (role of structural characteristic, 

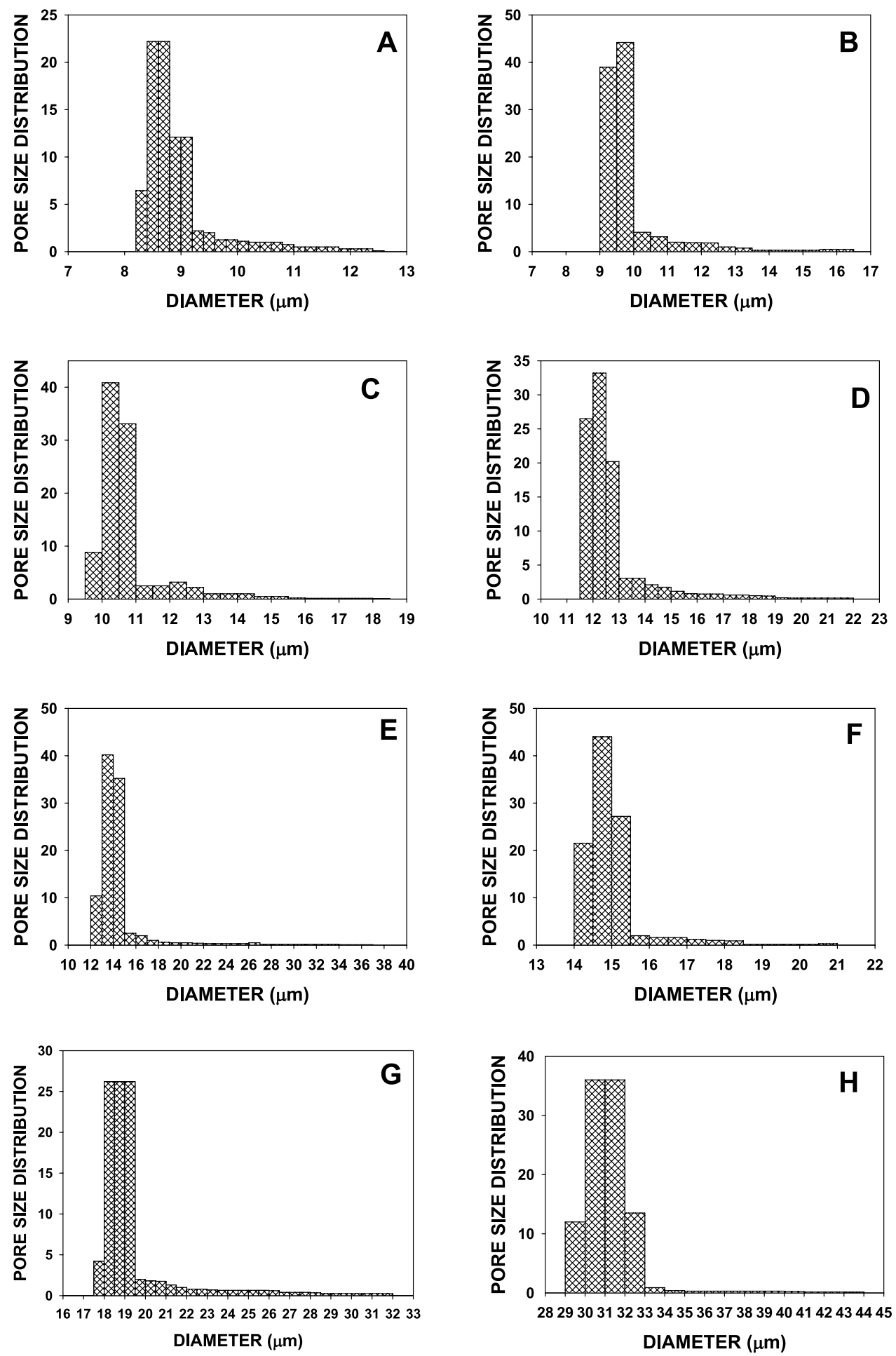

Figure 6. Pore size distribution of different sample (A-H) showing distribution of different diameter pore of the filter layer nonwoven PP-MB-NW fabric. $(\mathbf{A}-\mathbf{H})$ Plot showing pore size distribution vs. pore diameter of sample A, B, C, D, E, F, G and $\mathrm{H}$ using mercury porosimeter.

air permeability, through and open pore, and surface morphology of MB fibers) collectively contribute on the PFE of PP-MB-NW fabrics.

SEM characterization of PP-MB-NW fabric samples. Analysis of microstructure is important to explain the above finding of PP-MB-NW materials; hence scanning electron microscopy (SEM) characterization studies were performed. Figure 7, displays the SEM images of the PP-MB-NW fabrics. This characterization 


\begin{tabular}{|l|l|l|l|}
\hline S. no. & Sample code & Maximum pore size $(\boldsymbol{\mu m})$ & Mean pore size $(\boldsymbol{\mu m})$ \\
\hline 1 & A & 15.92 & 9.60 \\
\hline 2 & B & 12.49 & 8.80 \\
\hline 3 & C & 18.65 & 10.51 \\
\hline 4 & D & 22.32 & 12.34 \\
\hline 5 & E & 37.81 & 13.98 \\
\hline 6 & F & 20.81 & 14.85 \\
\hline 7 & G & 31.95 & 18.86 \\
\hline 8 & H & 43.80 & 31.07 \\
\hline
\end{tabular}

Table 4. Pore size distribution of different $M B$ sample $(\mathrm{A}-\mathrm{H})$ showing maximum and mean pore diameter of the filter layer.

\begin{tabular}{|c|c|c|c|}
\hline S. no. & Sample code & Total area in pores $11.79 \AA$ & $\begin{array}{l}\text { BJH desorption Cumulative volume of pores between } 17.0 \AA \text { and } 3000 \AA \\
\text { width }\end{array}$ \\
\hline 1 & A & 20.967 & 0.04332 \\
\hline 2 & B & 20.36 & 0.082 \\
\hline 3 & $\mathrm{C}$ & 13.397 & 0.060 \\
\hline 4 & $\mathrm{D}$ & 10.93 & 0.031 \\
\hline 5 & $\mathrm{E}$ & 6.852 & 0.016 \\
\hline 6 & $\mathrm{~F}$ & 4.50 & 0.008 \\
\hline 7 & G & 1.93 & 0.00168 \\
\hline 8 & $\mathrm{H}$ & 2.90 & 0.00542 \\
\hline
\end{tabular}

Table 5. Surface area analyzer study of $M B$ sample $(A-H)$ for the determination of open pore at one end having a dimension between $17-3000 \AA$ and total area in pore $11.79 \AA$.

studies were performed to investigate the surface morphology, the fiber diameter and density of entanglement. Since, 16 SEM images were taken for 8 samples $(\mathrm{A}-\mathrm{H})$, however, it is found that there is apparently no difference in the structural morphology of samples which are having approximately same PFE. Hence, the total samples A-H have been divided in to 4 categories based on PFE (i) PFE: 90-99 (Fig. 7A,B), (ii) 70-90 (Fig. 7C,D), (iii) 50-60 (Fig. 7E,F) and (iv) 20-30 (Fig. 7G,H), and only representative figure are presented here. As can be seen from the Fig. 7A,B (magnified image) which belong PFE to the range of 90-99, the rod shaped fibrous structures with non-uniform morphology was clearly observed with a wide range of diameters varied from 1 to $10 \mu \mathrm{m}$ of PP-MB-NW fibers with a high degree of entanglement with each other. The diameters of individual fibers in a web appear to change along the length of the fibers. The fiber junctions were also visible which was produced from thermal sticking, interlacing and branching of $\mathrm{MB}$ fibers. Compactness between the fibers decreases as we move down from sample $\mathrm{C}$ to $\mathrm{H}$. The fibers entanglement in sample $\mathrm{A}, \mathrm{B}$ and $\mathrm{C}$ are more when compared to rest of the sample which reflects the decrease in pore size of fibers due to entanglement ${ }^{49}$. Furthermore, in case of larger diameter fibers, the chances of entanglement are relatively lower and this contributes larger distances between fibers and also leads to larger diameter fibers ${ }^{49}$. As can be seen from Fig. 7G,H (magnified image) which belong to filtration efficiency of $20-30 \%$, less fibers per unit area which increase the distances between fibers. Though the fiber diameter is less in Fig. 7G,H as compared to rest of the sample, yet PFE is low due to low and wide spinneret orifice distributions which lead to increase the distance between the fibers during the manufacturing. Hence, it can be concluded from SEM images that PP-MB-NW fabrics which are having high entanglement, high fibers per unit area and the reduced distance between the fibers lead to higher filtration efficiency and this data support the findings of PFE and air permeability ${ }^{29-55}$.

Effect of charge on filtration efficiency of PP-MB-NW. In order to find out the effect of PP-MB-NW charge on filtration efficiency, resistance of sample A to $\mathrm{H}$ were measured utilizing Agilent 4339B, USA high resistance meter. The charge of various samples was calculated using resistance data. The charges of PP-MB-NW were shown in Fig. 8 and tabulated in Table 6. From the Table 6 and Fig. 8, it can be observed that there is a qualitative correlation between charge and filtration efficiency. From sample A to $\mathrm{C}$ the charge ranges from 30 to $31.78 \mathrm{nC}$ which gives more than $95 \%$ PFE, while in samples $\mathrm{D}$ to $\mathrm{H}$ the decremented trend is observed for both charge and PFE. Hence, from the above data it can be inferred that higher the surface charge on PP-MB-NW will lead to higher PFE. However, this result is only qualitative in nature and only using this parameter it is difficult to conclude about the PFE. Therefore, PFE largely depends on the cumulative effect of microstructural parameters, electrostatic charge, air permeability, diameter of through pore, availability of closed pore etc. 

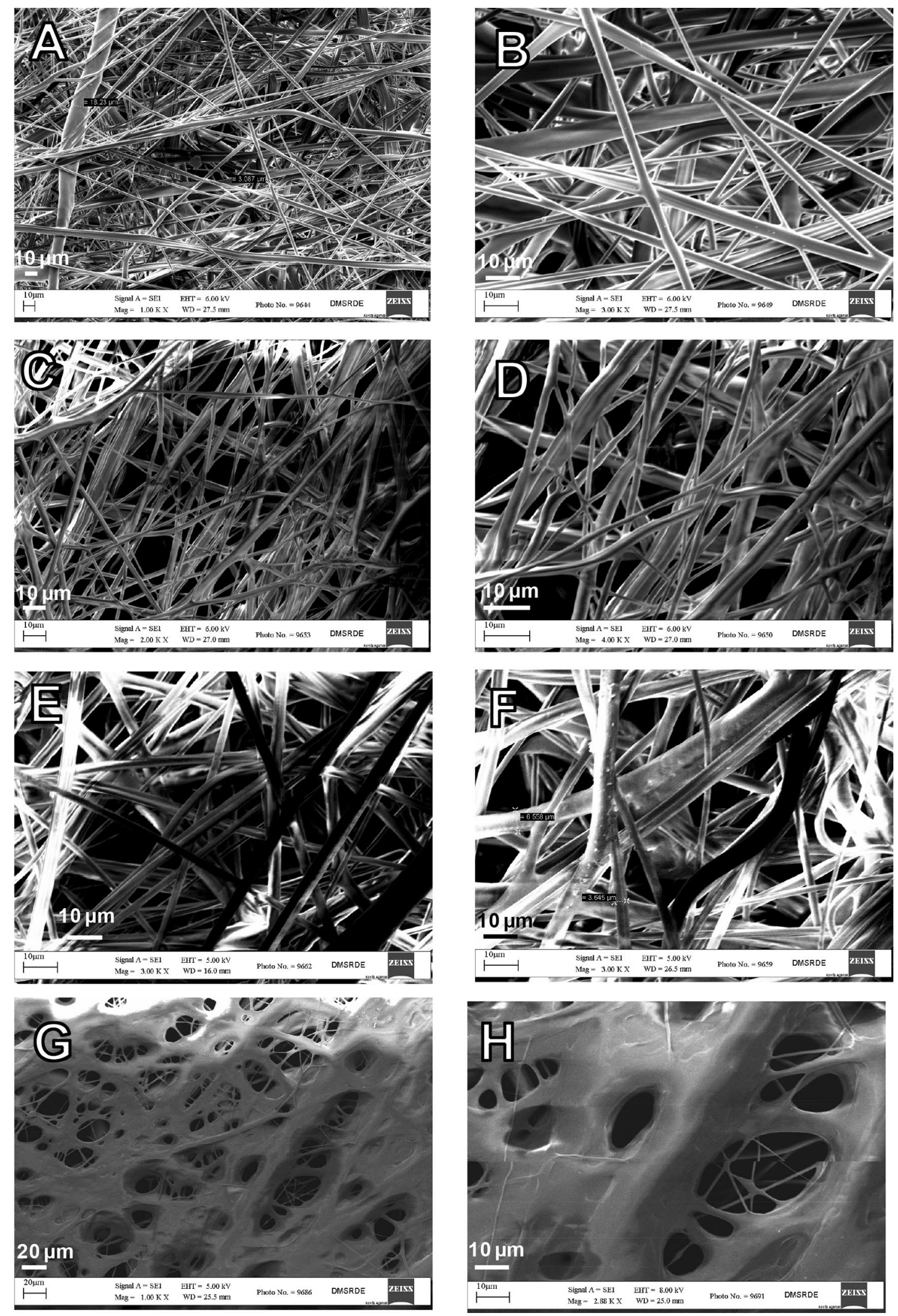

Figure 7. SEM images of the microscopic structure of various PP-MB-NW of sample A-H based on PFE $(\mathbf{A}, \mathbf{B})$ PFE: 90-99, (C,D) 70-90, (E,F) 50-60 and (G,H) 30-20. 


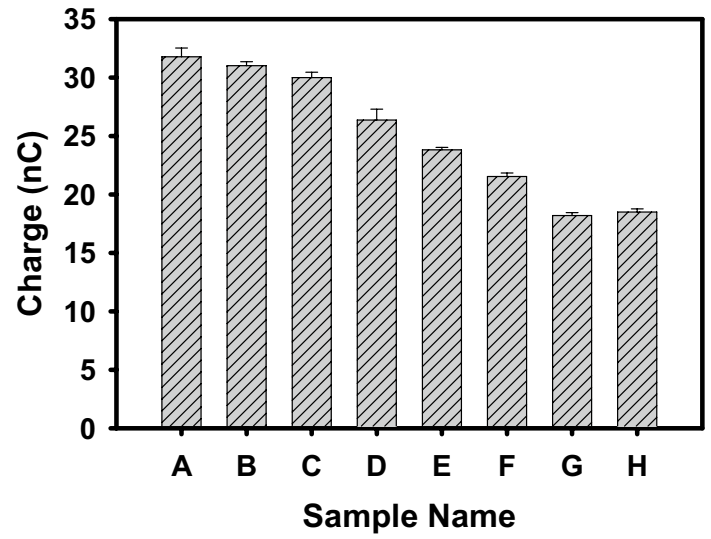

Figure 8. Charge of various PP-MB-NW of sample A-H (calculated using Standard EN 1149-1).

\begin{tabular}{|l|l|l|}
\hline Sample code & Charge $\mathbf{( n C )}$ & Filtration efficiency (\%) \\
\hline A & 31.7800 & 98.61 \\
\hline B & 31.0200 & 99.51 \\
\hline C & 30.0000 & 95.67 \\
\hline D & 26.3700 & 59.85 \\
\hline E & 23.8200 & 46.94 \\
\hline F & 21.5300 & 38.73 \\
\hline G & 18.2000 & 36.00 \\
\hline H & 18.5000 & 32.16 \\
\hline
\end{tabular}

Table 6. A comparison between filtration efficiency and charge of PP MB_NW samples A-H.

\section{Conclusions}

This study brings a useful insight to the selection of appropriate PP-MB-NW fabrics as effective air filter media, on the basis of their microstructural parameters such as porosity, pore diameter, fiber size, solid volume fraction, fiber arrangements, air permeability and pore size distribution. The filtration efficiency of different PP-MB-NW fabric samples is investigated in single and double layers combination for the particle size of $0.3,0.5$ and $1 \mu \mathrm{m}$. Surface area analysis was done for the first time in order to get more insight about the blind pore having a dimension between 17-3000 $\AA$ and total area in pore $11.79 \AA$ which were not possible with mercury porosimeter and found that the PP-MB-NW fabrics having total area in pores $11.79 \AA$ more than $10 \mathrm{~m}^{2} / \mathrm{g}$ with BJH desorption Cumulative volume of pores between $17.0 \AA$ and $3000 \AA$ width approx more than $0.031 \mathrm{~cm}^{3} / \mathrm{g}$ is exhibiting good filtration efficiency. The samples which are having the mean and maximum pore sizes in the range from 8.80 to $10.51 \mu \mathrm{m}$ and 12.49 to $18.65 \mu \mathrm{m}$, respectively are having a good filtration efficiency. From the above data, it can be inferred that the PP-MB-NW fabrics those are having low pore dia, high solid fraction volume, low air permeability are having high filtration efficiency against $0.3 \mu \mathrm{m}$ particle which reflects the importance of these structural parameters on PFE. Based on only one microstructural parameter, it is difficult to judge the performance of respiratory mask. However, the cumulative effect of these microstructural parameters which are interconnected with each other governs the performance of the PP-MB-NW fabrics in terms of filtration efficiency. We believe that this study will be very useful as it provides information and understanding about the core layer of respiratory mask, and provide a directive for the judicial selection of filter material to achieve high filtration efficiency to combat COVID-19.

Received: 9 January 2021; Accepted: 28 April 2021

Published online: 13 May 2021

\section{References}

1. Zangmeister, C. D., Radney, J. G., Vicenzi, E. P. \& Weaver, J. L. Filtration efficiencies of nanoscale aerosol by cloth mask materials used to slow the spread of SARS-CoV-2. ACS Nano 14, 9188-9200 (2020).

2. Jayaweera, M., Perera, H., Gunawardana, B. \& Manatunge, J. Transmission of COVID-19 virus by droplets and aerosols: A critical review on the unresolved dichotomy. Environ. Res., 109819 (2020).

3. Shiu, E. Y., Leung, N. H. \& Cowling, B. J. Controversy around airborne versus droplet transmission of respiratory viruses: Implication for infection prevention. Curr. Opin. Infect. Dis. 32, 372-379 (2019).

4. Tellier, R. Review of aerosol transmission of influenza A virus. Emerg. Infect. Dis. 12, 1657 (2006).

5. Yan, J. et al. Infectious virus in exhaled breath of symptomatic seasonal influenza cases from a college community. Proc. Natl. Acad. Sci. 115, 1081-1086 (2018). 
6. Baron, P. PowerPoint Presentation. US Department of Health and Human Services, Centers, 2010).

7. Bloom, D. E. \& Cadarette, D. Infectious disease threats in the twenty-first century: Strengthening the global response. Front. Immunol. 10, 549 (2019).

8. Ducharme, J. The coronavirus outbreak is now a public health emergency of international concern - Here's what that means. Available from: https://time.com/5774747/coronavirus-whopublic-health-emergency/ (2020).

9. Oliveira, A. C. d., Lucas, T. C. \& Iquiapaza, R. A. What has the COVID-19 pandemic taught us about adopting preventive measures? Texto Contexto-Enfermagem 29 (2020).

10. Cowling, B. J. \& Aiello, A. E. Public health measures to slow community spread of coronavirus disease 2019. J. Infect. Dis. 221, 1749-1751 (2020).

11. Van Doremalen, N. et al. Aerosol and surface stability of SARS-CoV-2 as compared with SARS-CoV-1. N. Engl. J. Med. 382, 1564-1567 (2020).

12. Wang, J., Pan, L., Tang, S., Ji, J. S. \& Shi, X. Mask use during COVID-19: A risk adjusted strategy. Environ. Pollut., 115099 (2020).

13. Centers for Disease Control and Prevention. Considerations for wearing masks. Accessed August 6, 2020. https://www.cdc.gov/ coronavirus/2019-ncov/prevent-getting-sick/cloth-face-cover-guidance.html (2020)

14. Davies, A. et al. Testing the efficacy of homemade masks: Would they protect in an influenza pandemic?. Disaster Med. Public Health Prep. 7, 413-418 (2013).

15. Worby, C. J. \& Chang, H.-H. Face mask use in the general population and optimal resource allocation during the COVID-19 pandemic. medRxiv (2020).

16. Tcharkhtchi, A. et al. An overview of filtration efficiency through the masks: Mechanisms of the aerosols penetration. Bioact. Mater. 6, 106-122 (2020).

17. Hutten, I. M. Handbook of nonwoven filter media. (Elsevier, 2007).

18. Control, C. f. D. \& Prevention. CDC Asthma, BRFSS 2006-Child Asthma Data Technical Information. http://www.cdc.gov/ BRFSS/ (2016).

19. National Institute for Occupational Safety and Health. NIOSH guide to the selection and use of particulate respirators certified under 42 CFR 84 (1996).

20. Lee, S.-A. et al. Particle size-selective assessment of protection of European standard FFP respirators and surgical masks against particles-tested with human subjects. J. Healthc. Eng. 2016 (2016).

21. Wu, H.-L., Huang, J., Zhang, C. J., He, Z. \& Ming, W.-K. Facemask shortage and the novel coronavirus disease (COVID-19) outbreak: Reflections on public health measures. EClinicalMedicine, 100329 (2020).

22. Chua, M. H. et al. Face masks in the new COVID-19 normal: Materials, testing, and perspectives. Research 2020 (2020).

23. Mukhopadhyay, A. in Composite Non-Woven Materials 164-210 (Elsevier, 2014).

24. King, M. W., Gupta, B. S. \& Guidoin, R. Biotextiles as Medical Implants (Elsevier, 2013).

25. Soltani, I. \& Macosko, C. W. Influence of rheology and surface properties on morphology of nanofibers derived from islands-inthe-sea meltblown nonwovens. Polymer 145, 21-30 (2018).

26. Brochocka, A., Nowak, A., Majchrzycka, K., Puchalski, M. \& Sztajnowski, S. Multifunctional polymer composites produced by melt-blown technique to use in filtering respiratory protective devices. Materials 13, 712 (2020).

27. Angadjivand, S. A., Brandner, J. M. \& Springett, J. E. (Google Patents, 2011).

28. Duran, K. et al. Investigation of the physical properties of meltblown nonwovens for air filtration. J. Text. Apparel/Tekstil ve Konfeksiyon 23 (2013).

29. Zhang, H., Liu, J., Zhang, X., Huang, C. \& Jin, X. Design of electret polypropylene melt blown air filtration material containing nucleating agent for effective PM2.5 capture. RSC Adv. 8, 7932-7941 (2018).

30. Respiratory protective devices - Filtering half masks to protect against particles - Requirements, testing, marking; German version EN 149:2001+A1:2009 (Beuth Verlag GmbH, Berlin, 23009)

31. Pradhan, A., Das, D., Chattopadhyay, R. \& Singh, S. Studies on air permeability of multi-constituent nonwovens. J. Text. Inst. 108, 788-793 (2017).

32. Geus, H.-G. in Advances in Technical Nonwovens 133-153 (Elsevier, 2016).

33. Rengasamy, S., Shaffer, R., Williams, B. \& Smit, S. A comparison of facemask and respirator filtration test methods. J. Occup. Environ. Hyg. 14, 92-103 (2017).

34. Rengasamy, S. et al. A comparison of total inward leakage measured using sodium chloride ( $\mathrm{NaCl})$ and corn oil aerosol methods for air-purifying respirators. J. Occup. Environ. Hyg. 15, 616-627 (2018).

35. Xu, R. Optical Particle Counting: Counting and Sizing. Particle Characterization: Light Scattering Methods, 182-222 (2002).

36. Jackson, G. W. \& James, D. F. The permeability of fibrous porous media. Can. J. Chem. Eng. 64, 364-374 (1986).

37. Xiao, Y. et al. Study on the relationship between structure parameters and filtration performance of polypropylene meltblown nonwovens. Autex Res. J. 1 (2019).

38. Zhu, G., Kremenakova, D., Wang, Y. \& Militky, J. Air permeability of polyester nonwoven fabrics. Autex Res. J. 15, 8-12 (2015).

39. Chauhan, V. K., Singh, J. P. \& Debnath, S. Investigation on filtration properties of polyester needle-punched dust filter. J. Text. Inst. 111, 897-905 (2020)

40. Payen, J. et al. Influence of fiber diameter, fiber combinations and solid volume fraction on air filtration properties in nonwovens. Text. Res. J. 82, 1948-1959 (2012).

41. Wang, Q., Maze, B., Tafreshi, H. V. \& Pourdeyhimi, B. Simulating through-plane permeability of fibrous materials with different fiber lengths. Model. Simul. Mater. Sci. Eng. 15, 855 (2007).

42. Sakthivel, S., Ezhil, A. J. \& Ramachandran, T. Development of needle-punched nonwoven fabrics from reclaimed fibers for air filtration applications. J. Eng. Fibers Fabr. 9, 155892501400900130 (2014).

43. Hassenboehler, C. B. A new method for pore structure analysis using air flow. Text. Res. J. 54, 252-261 (1984).

44. Epps, H. Prediction of single-layer fabric air permeability by statistical modeling. J. Test. Eval. 24, 26-31 (1996).

45. Ozturk, M. K., Nergis, B. \& Candan, C. A comparative study on air permeability properties of multilayered nonwoven structures. Int. J. Mater. Metal. Eng. 10, 1510-1513 (2017).

46. Moore IV, A. D. Air Permeability of Nonwoven Fabrics (Master's thesis). North Carolina State University, Raleigh, USA (2015).

47. Aydin, O. et al. Performance of fabrics for home-made masks against the spread of COVID-19 through droplets: A quantitative mechanistic study. Extreme Mech. Lett. 40, 100924 (2020).

48. Ciach, T. \& Gradoń, L. Multilayer fibrous filters with varied porosity and fibre diameter. JAerS 29, S935-S936 (1998).

49. Yesil, Y. \& Bhat, G. S. Porosity and barrier properties of polyethylene meltblown nonwovens. J. Text. Inst. 108, 1035-1040 (2017).

50. Dullien, F. A. Porous Media: Fluid Transport and Pore Structure (Academic Press, 2012).

51. Giesche, H. Mercury porosimetry. Handbook of porous solids, 309-351 (2002).

52. Theron, F., Lys, E., Joubert, A., Bertrand, F. \& Le Coq, L. Characterization of the porous structure of a non-woven fibrous medium for air filtration at local and global scales using porosimetry and X-ray micro-tomography. Powder Technol. 320, 295-303 (2017).

53. Rutledge, G. C., Lowery, J. L. \& Pai, C.-L. Characterization by mercury porosimetry of nonwoven fiber media with deformation. J. Eng. Fibers Fabr. 4, 155892500900400300 (2009).

54. Yu, J., Hu, X. \& Huang, Y. A modification of the bubble-point method to determine the pore-mouth size distribution of porous materials. Sep. Purif. Technol. 70, 314-319 (2010).

55. Shim, W. S. \& Lee, D. W. Quality variables of meltblown submicron filter materials (2013). 


\section{Acknowledgements}

The authors thank Dr. D. K. Dubey, Director, Defence Research and Development Establishment, DRDO, Gwalior-474002 (India) for his keen interest and encouragement. DRDE Accession no. of this manuscript is DRDE/PD/27/2020.

\section{Author contributions}

L.K.P.: methodology, validation, data analysis (surface area), drawing of images and manuscript writing; V.V.S.: conceptualization, methodology, writing - review and editing and supervision; P.K.S.: review and editing; D.M.: data analysis (air permeability and GSM of melt blown); U.B.: experiment for PFE; M.S.: review and editing. K.G.: review and editing; V.B.T.: review and editing; K.A.: SEM characterization of samples.

\section{Competing interests}

The authors declare no competing interests.

\section{Additional information}

Correspondence and requests for materials should be addressed to V.V.S.

Reprints and permissions information is available at www.nature.com/reprints.

Publisher's note Springer Nature remains neutral with regard to jurisdictional claims in published maps and institutional affiliations.

(c) (i) Open Access This article is licensed under a Creative Commons Attribution 4.0 International cc) License, which permits use, sharing, adaptation, distribution and reproduction in any medium or format, as long as you give appropriate credit to the original author(s) and the source, provide a link to the Creative Commons licence, and indicate if changes were made. The images or other third party material in this article are included in the article's Creative Commons licence, unless indicated otherwise in a credit line to the material. If material is not included in the article's Creative Commons licence and your intended use is not permitted by statutory regulation or exceeds the permitted use, you will need to obtain permission directly from the copyright holder. To view a copy of this licence, visit http://creativecommons.org/licenses/by/4.0/.

(C) The Author(s) 2021 